\title{
Petrophysical characterization of Albian carbonate reservoir in Campos Basin using a multivariate approach with well logs and laboratory measurements
}

Raphael Silva \& Abel Carrasquilla - UENF/CCT/LENEP, Macae - RJ, Brazil

Copyright 2016, SBGf - Sociedade Brasileira de Geofísica

Este texto foi preparado para a apresentação no VII Simpósio Brasileiro de Geofísica, Ouro Preto, 25 a 27 de outubro de 2016. Seu conteúdo foi revisado pelo Comitê Técnico do VII SimBGf, mas não necessariamente representa a opinião da SBGf ou de seus associados. É proibida a reprodução total ou parcial deste material para propósitos comerciais sem prévia autorização da SBGf.

\section{Summary}

An Albian carbonate reservoir from Oilfield B in Campos Basin was characterized using a database of geophysical and petrophysical laboratory data. Porosity, permeability and water saturation logs were derived from the reference well and adjusted to laboratory measurements. Hereafter, statistics, regression, clustering and cross graphic techniques supported the initial interpretation, helping to determine electrofacies and flow zones, as well as, improved the experimental data fits. Finally, all of this methodology was successfully used to predict the same petrophysical parameters in a neighboring well without laboratory data.

\section{Introduction}

Campos is the most producing oil basins in the Brazilian continental margin, accounting for over $80 \%$ of national production (Figure 1). In it there are fields with the presence of carbonate Albian reservoirs with medium porosity and permeability of $250 \mathrm{mD}$ and $25 \%$, respectively. These reservoirs are characterized as being heterogeneous materials, having a textural variety and are typically broken, which leads to a generally low recovery factor and complex relationship between the properties of the rock and geophysical data. For both, characterize carbonate reservoirs through a combination study of their petrophysical properties and their well geophysical logs provides a fundamental understanding of its geometry and its dynamic properties (Bruhn et al., 2003).

While some porosity and other physical properties are routinely evaluated from well log, the measurement in situ of permeability is usually not feasible at low cost, being made by formation tests. Furthermore, it is recognized that permeability is a property depending on the measuring scale, so that its measurement on cores cannot be directly used for the evaluation of the permeability in the reservoir scale. Thus, the ability to estimate petrophysical properties of a reservoir rock from other more easily measured parameters or by means of laboratory tests is of great value to the oil industry. The petrophysical characterization using geophysical logs, for example, is of great importance to the discovery of new hydrocarbon reservoirs and aims to reduce the uncertainty and risks associated with oil exploration. Just as important are the early stage of development of an oil field, helping to define the best development strategy through the petrophysical and geological characterization (Lucia, 1999).
So, well logs and analysis of rock samples in the laboratory are methods widely used to evaluate the physical properties of geological formations in the petrophysical characterization of carbonate reservoirs (Aguilera \& Aguilera, 2001). The data resolution and the spatial coverage in these two methods, combined with the amount of measured parameters, occur in different ranges to obtain knowledge of the lithology and subsurface structural information (Shenawi et al., 2007). Thus, the proposed study aims to explore the advantages of these two techniques, even adding the geological interpretation, to evaluate, from the petrophysical point of view, a set of data from a carbonate reservoir in Oilfield B in Campos Basin.

\section{Materials and Methods}

The methodology used in this study was as follows:

a) Initially, two wells were selected in this field, called $X$ and $Y$, having the first well logs and laboratory petrophysical data and the second only well logs. The well $X$ was used as a reference and $Y$ as a blind test, whereas the distance between them is small $(180 \mathrm{~m})$, which have similar geological characteristics.

b) Gamma rays, resistivity, sonic, density and neutron logs in reference well $X$ were interpreted by deriving petrophysical parameters such as porosity, permeability and saturation, which were compared with the same parameters measured in the laboratory, allowing a more reliable reservoir characterization.

c) These initial estimates were subject to statistical analysis using parameters such as maximum, minimum, average, median, mode, standard deviation, and histograms, which served to have a broader understanding of these petrophysical parameters.

d) Linear regression and multiple linear regression techniques were used to estimate both the porosity from neutron porosity, density, sonic, such as permeability, exploiting its linear dependence of porosity.

e) Cluster Analysis for Rock Typing module of Interactive Petrophysics software (Senergy, 2014) was used to estimate porosity and permeability values aiming at a better correlation with laboratory data.

f) Cross-correlation, Pickett and Winland graphs were built to assist the initial interpretation, helping in determining electrofacies, location of flow areas and better adjusting with laboratory parameters.

g) Finally, all the methodology applied to the well reference $X$ was used to infer the same petrophysical parameters in a blind test, nearby well $\mathrm{Y}$, which lacked laboratory data.

\section{Results}

The histograms of both well logs indicate that there are logs with mono (density, neutron porosity and sonic) and bimodal (gamma and resistivity rays) characteristics (Figure 2), and that the correlation between the two wells showed that reservoirs with hydrocarbons are deeper in 
the well X (Figure 3). Laboratory data show a strong linear dependence between permeability and porosity (Figure 4 ), with the porosity data ranging from $0.7-35 \%$ by focusing between $20-24 \%$, as the permeability range between 0.1 - $40 \mathrm{mD}$ and focus between 1.6 - $1.8 \mathrm{mD}$ (Figure 5).

The results of the clustering to density, neutron and sonic logs in wells $X$ and $Y$ have up to 10 electrofacies (Figure 6 ), wherein the depths with those values above 9, have the best reservoir characteristics (Figure 7). The determination of these electrofacies served as guidance to make a better estimate of the porosities and permeabilities derived from these logs. To the well $X$, when comparing with laboratory data, we observe fine adjustments to all estimates of porosity and permeability, but multiple linear regression resulted to be the best be compared with laboratory data (Figure 8).

Pickett (1966) plot proved to be similar in both wells, which served to estimate the value of the parameter $m$ from the Archie Equation $(m=2)$ and hence the water saturation using Archie's equation as well as the volume of clay VSHALE, which resulted with low values $(<20 \%)$. The water resistivity formation $\mathrm{R}_{w}$ of this equation was estimated using the Schlumberger (2013) charts (Figure 9). The best correlation between calculated porosity and permeability data and laboratory data using multiple linear regression it was used to generate the Winland graphic (1972). Three flow units in Albian reservoir of well X were identified in this graphic and pore throats with values lower than $2 \mathrm{~mm}$ (Figure 10).

The first flow unit is characterized by having micro pores, with a good total porosity, but very low permeability. The second has micro pores and meso pores, with good porosity but low permeability. The third presents meso pores, with great porosity, reasonable permeability and high oil saturation, thus constituting itself in the unit with better characteristics for hydrocarbon production (Figure 11). The same 3 units of flow are identified in well $Y$, allowing the identification points which the porosity and permeability have incorrectly calculated by multiple linear regression (Figure 12).

\section{Conclusions}

In this work, we characterize the Albian carbonate reservoirs of Oilfield B in Campos Basin integrating the results derived from the interpretation of well logs with petrophysical properties measured in the laboratory. We have shown that the proper use of this database, using the plenty of well logs in front of the sparseness and targeting of laboratory tests, taking at the same time the advantage of the mathematics and geological interpretations, lead us to derive a wide range of petrophysical parameters that give us a broad view of the reservoir. This results in greater confidence in the estimates, which allowed us to extend the obtained results from the reference Well $X$ to Well $Y$, which is considered as a blind test. In the study, this extension was made successfully only for one well, however, the methodology can be spread over the next wells with similar geology within the same reservoir.

\section{Acknowledgements}

The authors would like to thank the Carbonates Science, Training and Technology System (SCTC) of Petrobras for their cooperation in providing the data to publish this work.

\section{References}

- Aguilera, R. \& Aguilera, M. 2001. The integration of capillary pressures and Pickett plots for determination. SPE Conference, paper no. 71725.

- Bruhn C., Gomes J., Lucchese C. \& Johann P. 2003. Campos basin: reservoir characterization and management - Historical overview and future challenges. Offshore Technology Conference, Houston, Texas, paper OTC 15220, $14 \mathrm{p}$.

- Lucia, F. 2007. Carbonate reservoir characterization. Springer - Verlag, Berlin, Heidelberg, $336 \mathrm{p}$.

- LR Senergy. 2014. Interactive Petrophysics v4.3, Online user's manual (http://www.Ir-senergy.com/software/ip).

- Pickett, G. 1966. A Review of current techniques for determination of water saturation from logs. JPT, vol. 18. p. 1425-1433.

- Schlumberger. 2013. Log interpretation charts. Educational Services. USA, $306 \mathrm{p}$.

- Shenawi, S.; White, J.; Elrafie, E. \& El-Kilany, K. 2007. Permeability and water saturation distribution by lithologic facies and hydraulic units: a reservoir simulation case study. Presented at the SPE Middle East Oil and Gas Show and Conference, Manama, Bahrain, SPE105273

- Silva, R. 2016. Petrophysical characterization of an Albian carbonate reservoir using well logs and laboratory measurements. Master Thesis, UENF/CCT/LENEP, Macaé - RJ, 157 p. (In Portuguese).

- Winland, H. 1972. Oil accumulation in response to pore size changes, Weyburn field, Saskatchewan: Amoco Production Company Report F72-G-25, 20 p. (Unpublished).

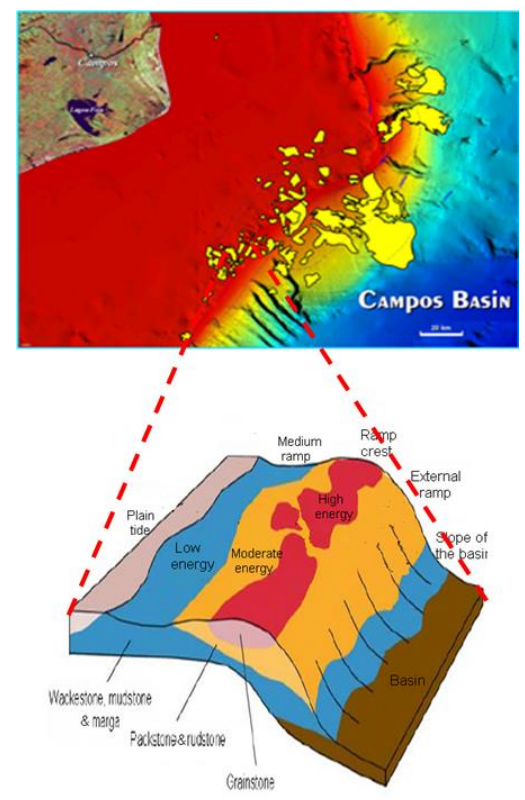

Figure 1. Albian carbonate reservoirs in Campos Basin (modify from Bruhn et al., 2003) 

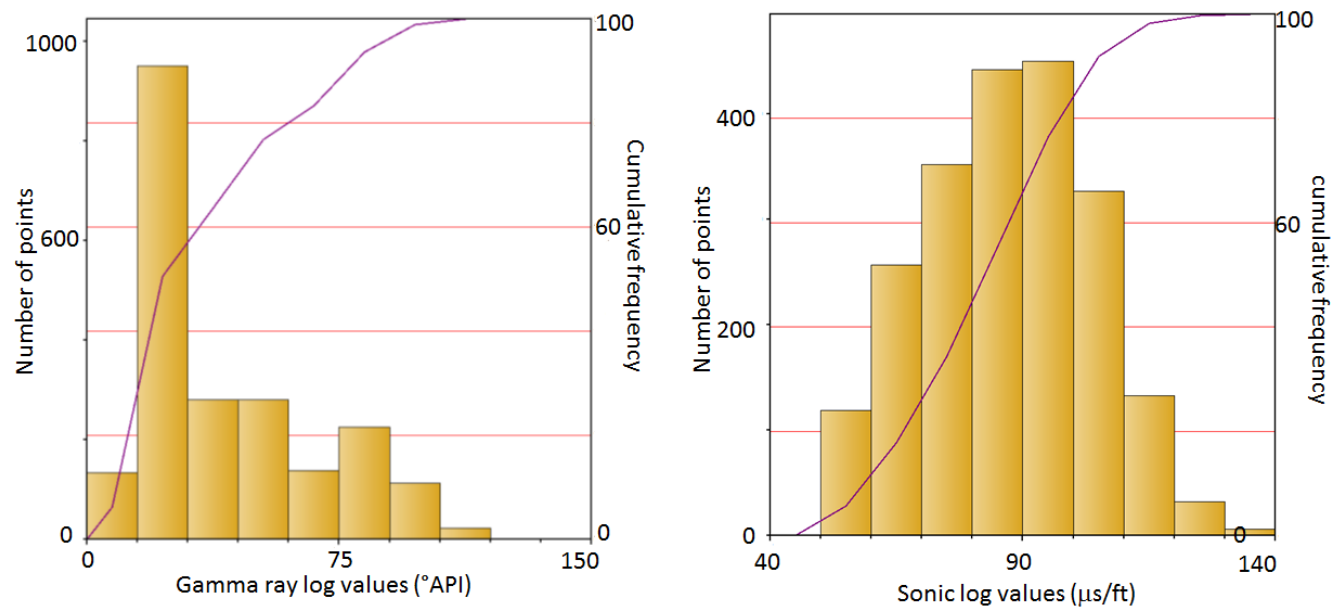

Figure 2. Histograms of gamma rays (left) and sonic (right) logs of Well X - Oilfield B.

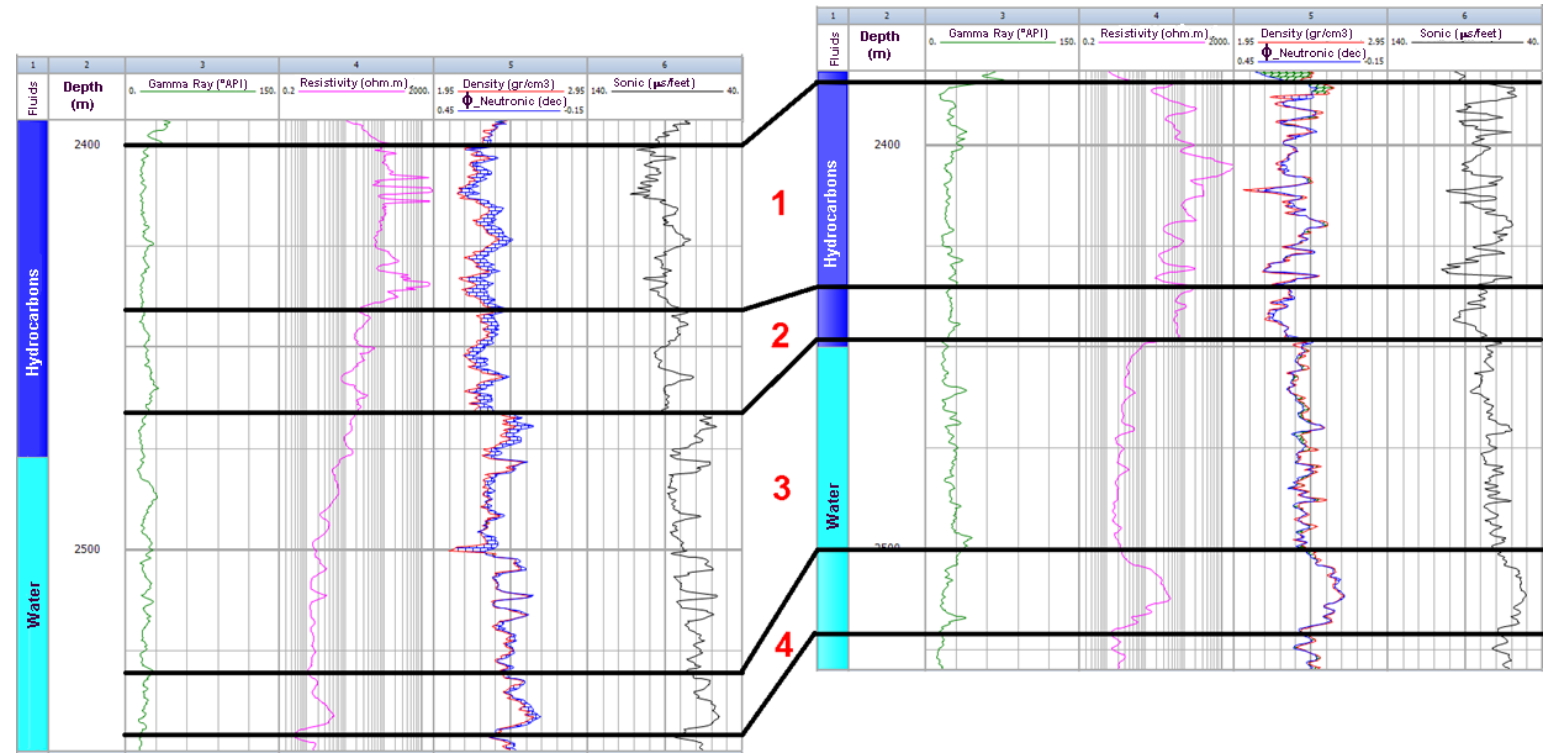

Figure 3. Correlation between gamma, resistivity, density, neutron porosity and sonic logs to the wells $X$ and $Y$ of Oilfield B in Campos Basin. The red numbers 1 to 4 indicate areas with similar characteristics.

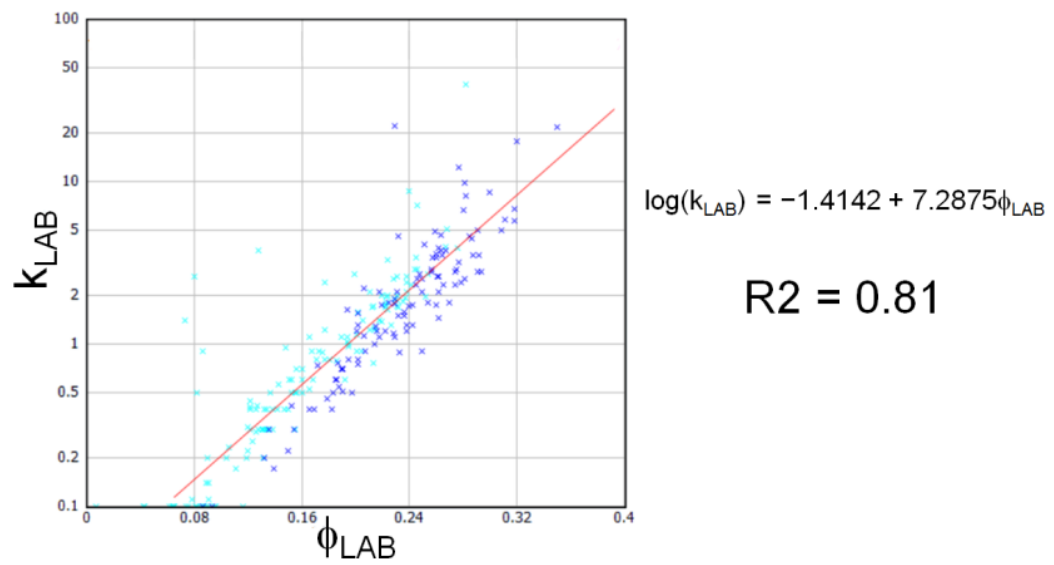

Figure 4. Porosity ( $\phi\llcorner\mathrm{LB})$ and permeability $\left(\mathrm{K}_{\mathrm{LAB}}\right)$ laboratory data crossplot for Well $\mathrm{X}$ showing a strong direct relationship, with dark blue signifying the hydrocarbon zone and liaht blue the aauifer. 

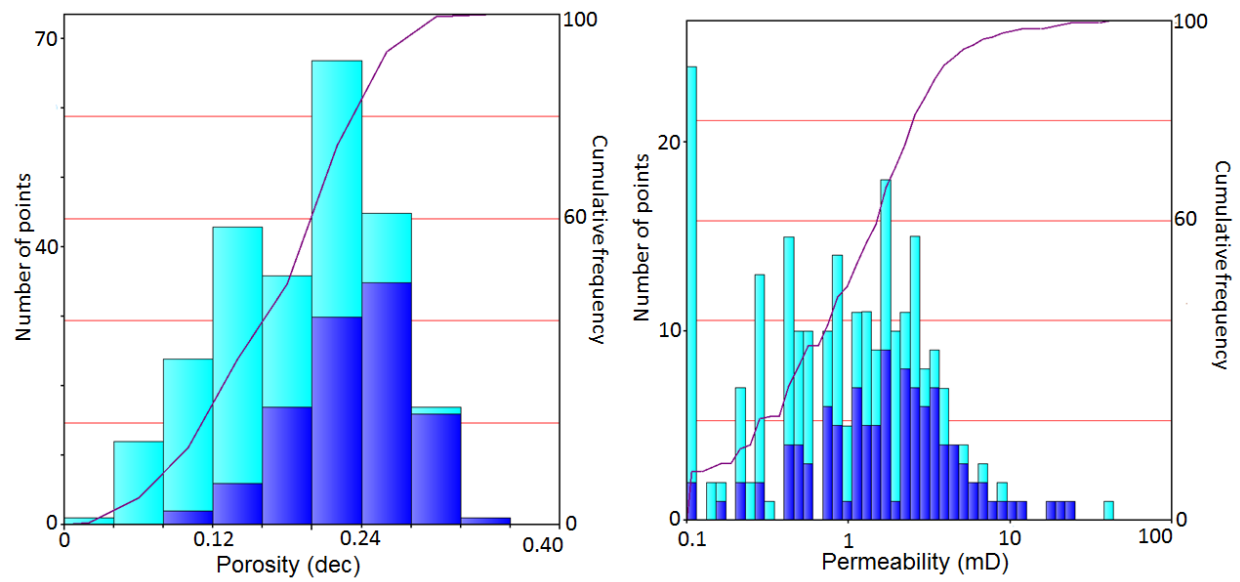

Figure 5. Porosity $\left(\phi\llcorner A B)\right.$ and permeability $\left(K_{\llcorner A B}\right)$ laboratory histograms for Well $X$ with dark blue meaning the hydrocarbon zone and light blue the aquifer.

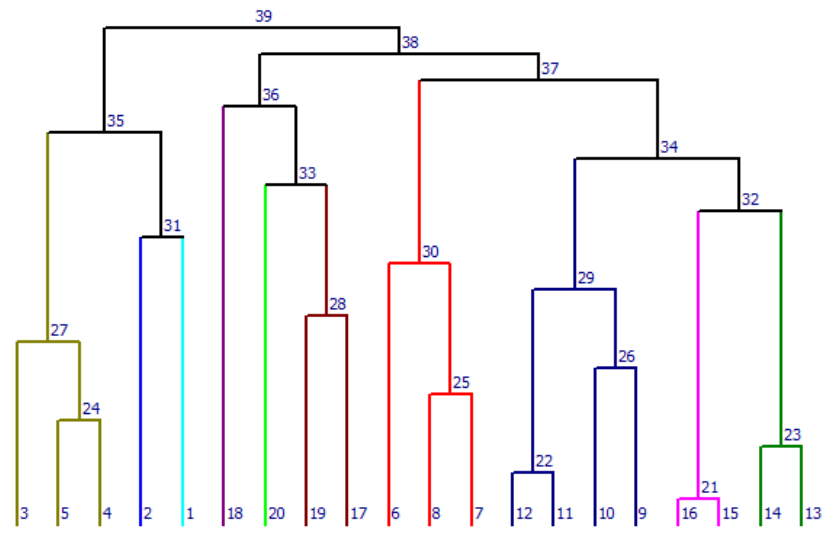

Figure 6. Clusters in 10 different colors, considering density, neutron and sonic logs of Well $X$, using the method of the sum of the square of the distance.
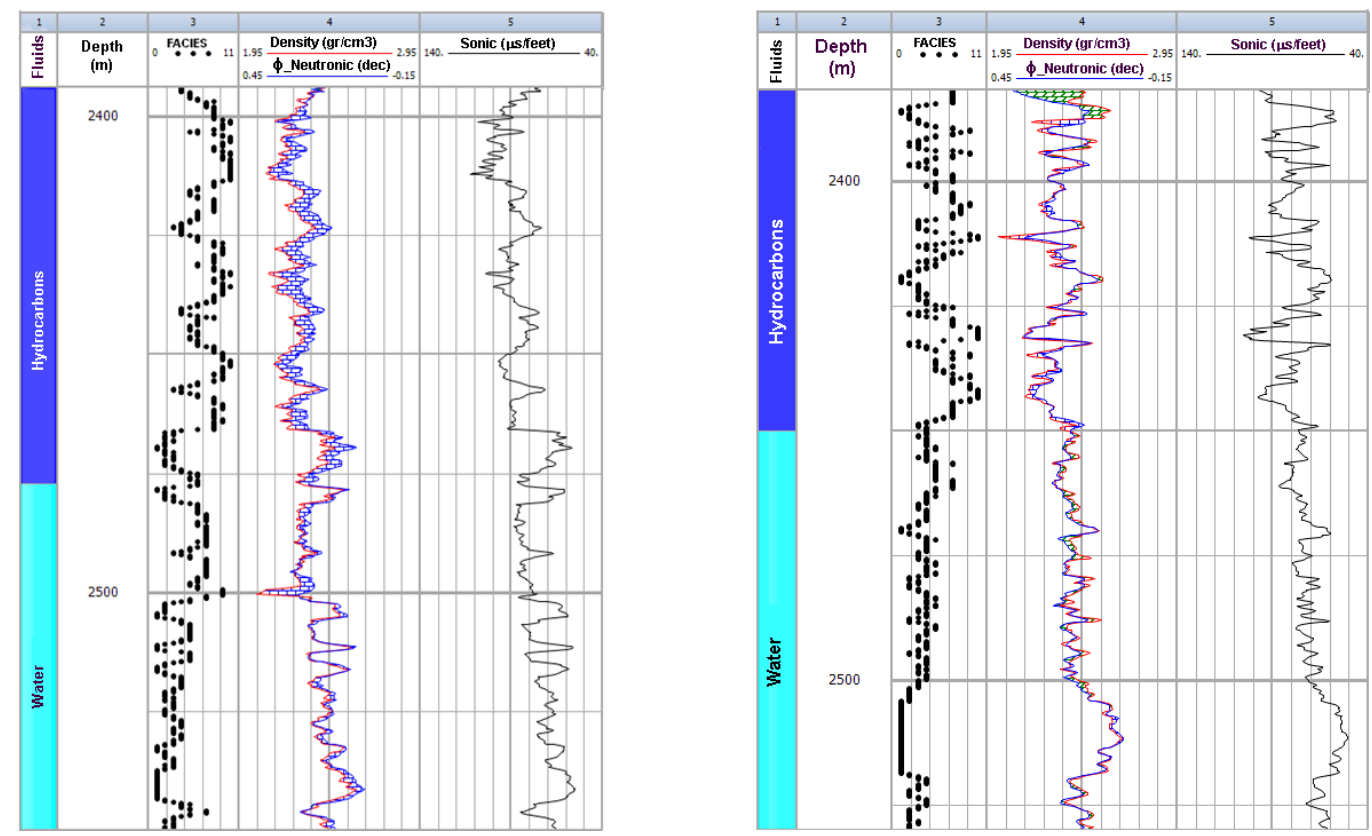

Figure 7. In the third track electrofacies for Well X (left) and Well Y (right) for each depth. 

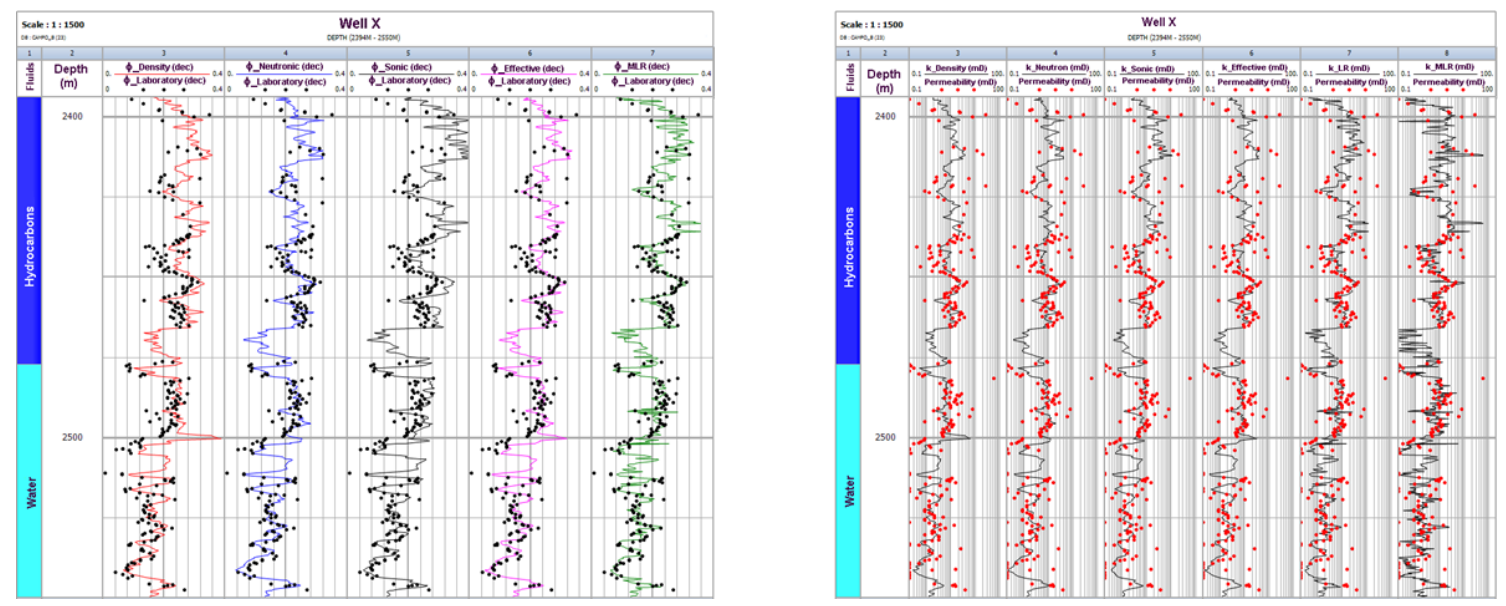

Figure 8. Estimated values of porosity (left) and permeability (right) for Well X compared with the respective data measured in the laboratory, using the estimates of density, neutron, sonic, effective, linear regression and multiple linear regression porosities.
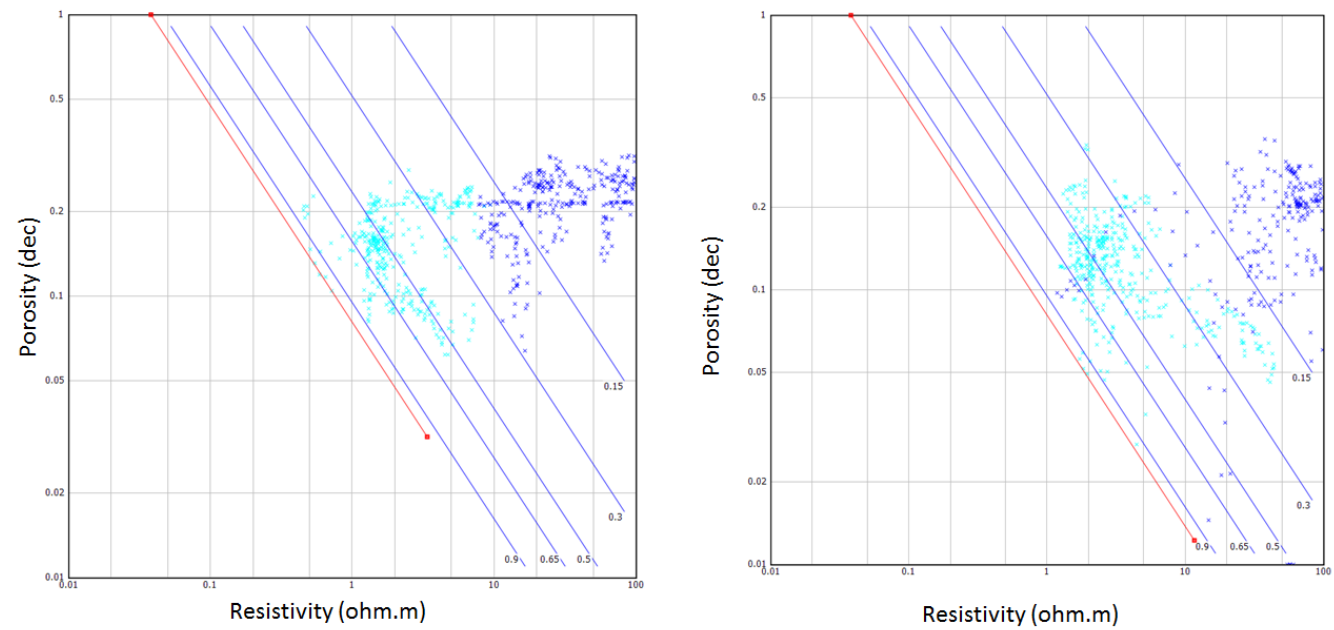

Figure 9. Pickett graph for Well $X$ (left) and Well $Y$ (right) of the Oilfield B, with light blue signifying the aquifer and dark blue zone hydrocarbon. Slopes of the straight lines are the parameter $m$ of Archie equation $(m=2)$.
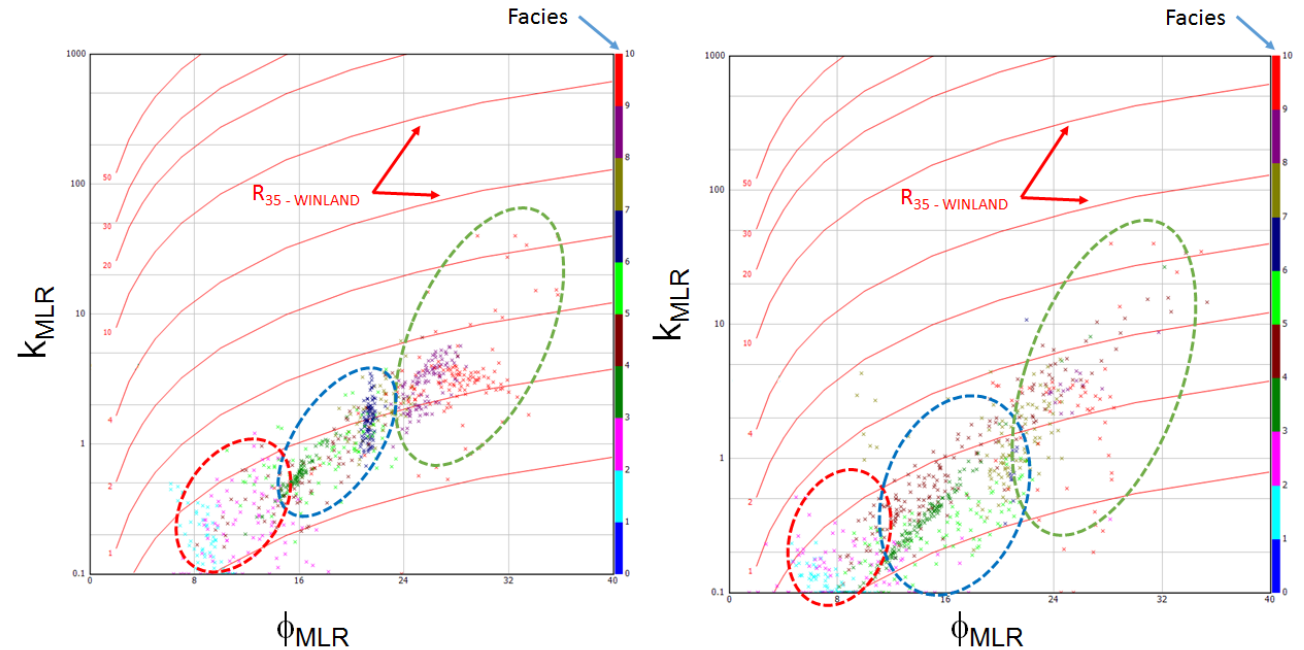

Figure 10. Winland graph for Well X (left) and Well $Y$ (right) of the Oilfield B, where the different colors mean different electrofacies, red curves are the pore throat radius and ellipses mean flow zones, with red being the zone 1 , blue is the zone 2 and green the zone 3 . 


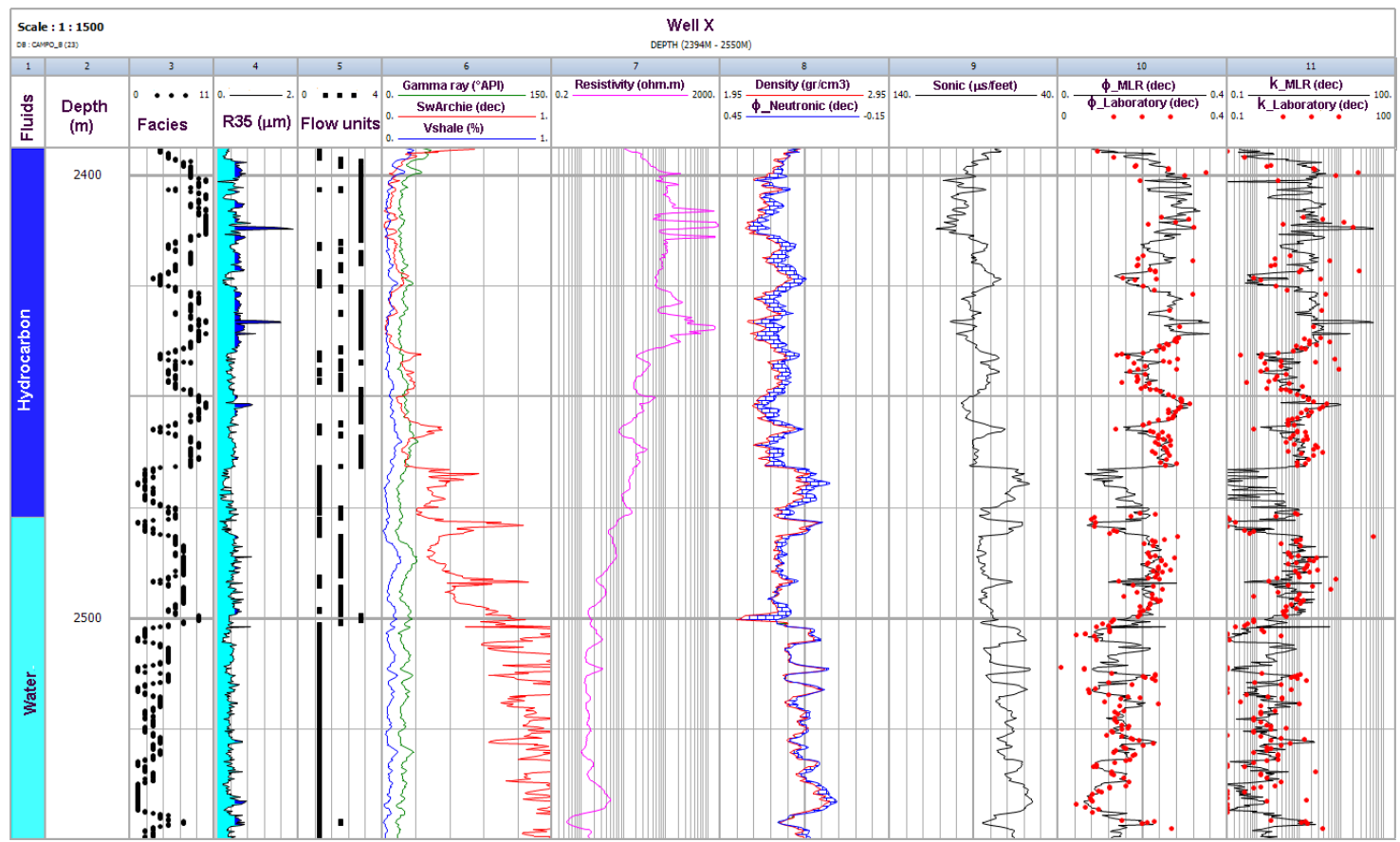

Figure 11. Complete interpretation for Well $\mathrm{X}$, highlighting the electrofacies in the third track, the pore throat radius in the fourth, the flow units in the fifth and water saturation and volume of clay in the sixth.

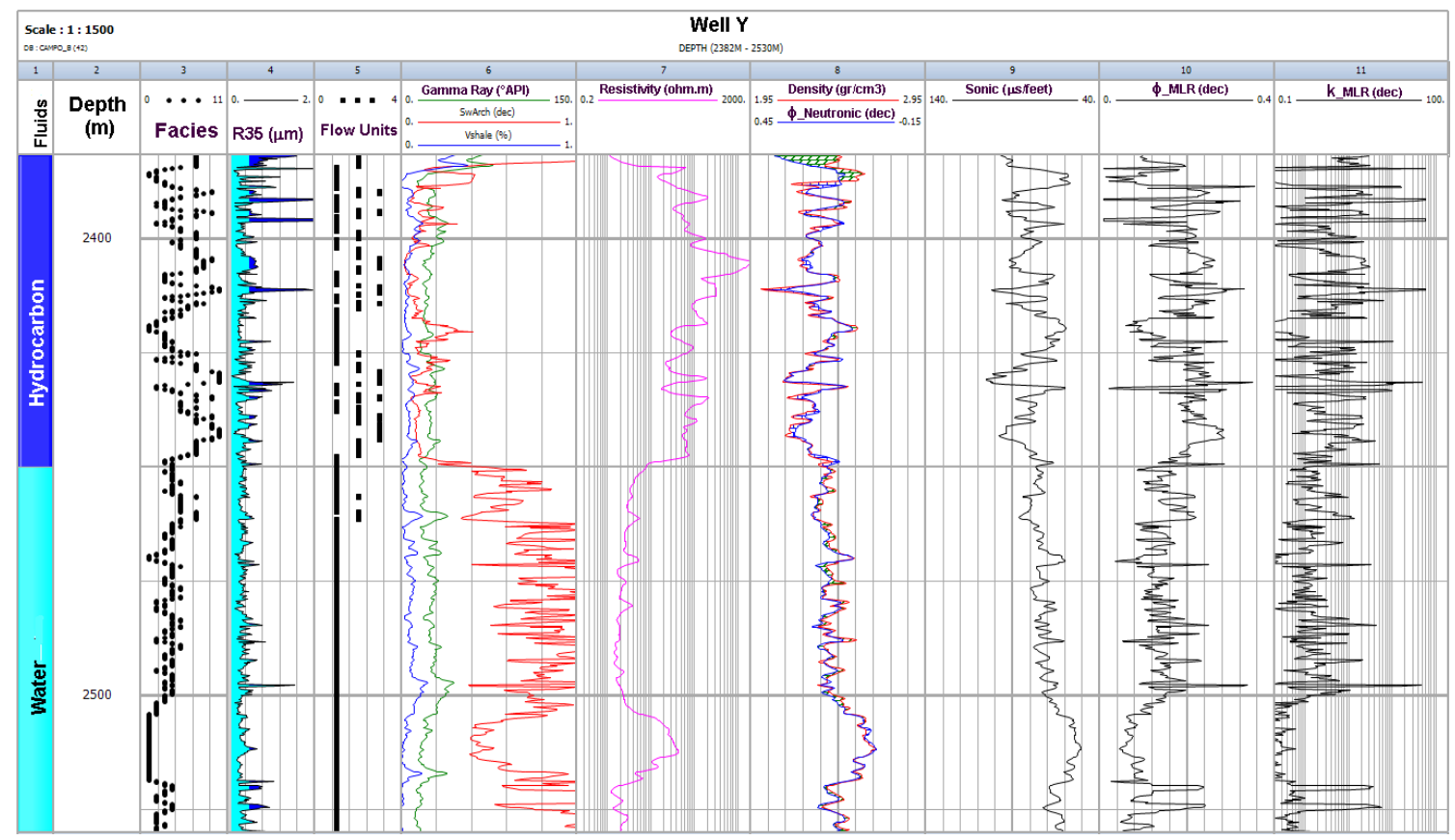

Figure 12. Full interpretation of the Well $\mathrm{Y}$, highlighting electrofacies in the third track, the pore throat radius in the fourth, flow units in fifth and water saturation and volume of clay in sixth. 